\title{
Placing plant-soil feedbacks in the context of plant community growth
}

\author{
Josephine Grenzer ${ }^{1}$, Andrew Kulmatiski ${ }^{1}$, Leslie Forero ${ }^{1}$, Anne Ebeling ${ }^{2}$, Nico Eisenhauer ${ }^{3}$, \\ and Jeanette Norton ${ }^{1}$ \\ ${ }^{1}$ Utah State University \\ ${ }^{2}$ University Jena \\ ${ }^{3}$ Universitat Leipzig Fakultat fur Biowissenschaften Pharmazie und Psychologie
}

April 18, 2021

\begin{abstract}
1. Plant-soil feedback (PSF) has gained attention as a mechanism promoting plant growth and coexistence. However, because most PSF research has measured monoculture growth in greenhouse conditions, field-based PSF experiments remain an important frontier for PSF research. 2. Using a four-year, factorial field experiment in Jena, Germany, we measured the growth of nine grassland species on soils conditioned by each of the target species (i.e., PSF). Plant community models were parameterized with or without these PSF effects, and model predictions were compared to plant biomass production in new and existing diversity-productivity experiments. 3. Plants created soils that changed subsequent plant biomass by $36 \%$. However, because they were both positive and negative, the net PSF effect was $14 \%$ less growth on 'home' than 'away' soils. At the species level, seven of nine species realized non-neutral PSFs, but the two dominant species grew only $2 \%$ less on home than away soils. At the species*soil type level, 31 of 72 PSFs differed from zero. 4. In current and pre-existing diversity-productivity experiments, nine-species plant communities produced 37 to $29 \%$ more biomass than monocultures due primarily to selection effects. Null and PSF models predicted 29 to $28 \%$ more biomass for polycultures than monocultures, again due primarily to selection effects. 5. Synthesis: In field conditions, PSFs were large enough to be expected to cause roughly $14 \%$ overyielding due to complementarity, however, in plant communities overyielding was caused by selections effects, not complementarity effects. Further, large positive and large negative PSFs were associated with subdominant species, suggesting there may be selective pressure for plants to create neutral PSF. Broadly, results highlighted the importance of testing PSF effects in communities because there are several ways in which PSFs may be more or less important to plant growth in communities than suggested from simple PSF values.
\end{abstract}

Placing plant-soil feedbacks in the context of plant community growth

Josephine Grenzer*1, Andrew Kulmatiski ${ }^{1}$, Leslie Forero ${ }^{1}$, Anne Ebeling ${ }^{2}$, Nico Eisenhauer ${ }^{3,4}$, Jeanette Norton $^{5}$

${ }^{1}$ Department of Wildland Resources and the Ecology Center, Utah State University, 5230 Old Main Hill, Logan, UT 84322-5230, USA

${ }^{2}$ Institute of Ecology and Evolution, University of Jena, Dornburger Strasse 159, 07743 Jena, Germany

${ }^{3}$ German Centre for Integrative Biodiversity Research (iDiv), Halle-Jena-Leipzig, Puschstrasse 4, 04103 Leipzig, Germany

${ }^{4}$ Institute of Biology, University of Leipzig, Puschstrasse 4, 04103 Leipzig, Germany 
${ }^{5}$ Department of Plant, Soils and Climate, Utah State University, 4280 Old Main Hill, Logan, UT 84322-5230, USA

\section{*For correspondence:}

Email: andrew.kulmatiski@usu.edu

Abstract

1. Plant-soil feedback (PSF) has gained attention as a mechanism promoting plant growth and coexistence. However, most PSF research has measured monoculture growth in greenhouse conditions. Translating PSFs into effects on plant growth in field communities remains an important frontier for PSF research.

2. Using a four-year, factorial field experiment in Jena, Germany, we measured the growth of nine grassland species on soils conditioned by each of the target species (i.e., PSF). Plant community models were parameterized with or without these PSF effects, and model predictions were compared to plant biomass production in new and existing diversity-productivity experiments.

3. Plants created soils that changed subsequent plant biomass by $36 \%$. However, because they were both positive and negative, the net PSF effect was $14 \%$ less growth on 'home' than 'away' soils (i.e., the average PSF value was -0.14). At the species level, seven of nine species realized non-neutral PSFs. At the species*soil type level, 31 of 72 PSFs differed from zero. The two dominant species grew only $2 \%$ less on home than away soils.

4. In current and pre-existing diversity-productivity experiments, nine-species plant communities produced 37 to $29 \%$ more biomass than monocultures due primarily to selection effects. Null and PSF models predicted 29 to $28 \%$ more biomass for polycultures than monocultures, again due primarily to selection effects.

5. Synthesis: In field conditions, PSFs were consistent and large enough to be expected to affect plant growth and coexistence. However, overyielding in plant communities was caused by selection effects so complementarity effects caused by PSF were not important in these communities. We identified several reasons that even large PSFs may not affect plant productivity. In general, we found that both large positive and large negative PSFs were associated with subdominant species. Because of this, we suggest there may be selective pressure for plants to create neutral PSF. Broadly, testing PSFs in plant communities in field conditions, highlighted new directions for understanding PSF effects in communities in the context of other species traits.

Keywords: aboveground-belowground interactions, biodiversity-ecosystem functioning, dominance, plant community model, plant identity, biomass

\section{Introduction}

Plant-soil feedbacks (PSFs) have gained attention over the past 25 years as a potential mechanism of plant growth and coexistence (Bever 1994; van der Putten et al. 2013). Yet, most PSF research has been performed using plant monocultures in greenhouse conditions (Kulmatiski et al. 2008; Forero et al. 2019). Recent work suggests that these greenhouse experiments provide little insight into plant growth in field communities (Forero et al. 2019; Reinhart et al. 2021). There remains, therefore, a need to better understand the role of PSF in plant communities in the field (Kulmatiski and Kardol 2008; Lekberg et al. 2018).

One robust trait of plant communities that may be, at least in part, explained by PSF is that productivity tends to increase with diversity (Kulmatiski et al. 2012; Tilman et al., 2001; Weisser et al., 2017). It has long been thought that the positive diversity-productivity relationship can be explained because species extract resources in different times or places (i.e., niche partitioning or complementarity; Hector et al., 1999; Loreau \& Hector, 2001; Tilman et al., 1997). This mechanism can explain both species coexistence and why more diverse communities are more productive, because they more fully exploit resource space (Barry et al., 2019; 
Loreau, Naeem, Inchausti, Bengtsson, Grime, et al., 2001). However, resource complementarity has been found to be insufficient to explain either the extent of, or variation in, diversity-productivity relationships (Barry et al., 2019; Hector et al., 1999; Schnitzer et al., 2011). For example, despite overall positive diversity effects, some species and communities often underyield in diversity-productivity experiments (Hector et al., 2002). As a result, there has been interest in discovering additional mechanisms behind diversity-productivity relationships (Eisenhauer, Reich, \& Scheu, 2012; Loreau et al., 2001).

Selection effects and disease accumulation have been suggested as additional mechanisms underlying positive diversity-productivity relationships (Loreau \& Hector 2001; Maron et al. 2011; Schnitzer et al. 2011). Selection effects occur if species with 'selected' traits disproportionately affect mixtures at the expense of other species (Fox et al., 2005, Loreau \& Hector, 2001, Roscher et al. 2009). Disease accumulation can cause overyielding if species-specific diseases accumulate and suppress plant growth more in low-diversity communities than high-diversity communities (i.e., pathogen dilution; Maron et al., 2011; Mommer et al., 2018; Schnitzer et al., 2011). However, neither selection effects nor disease accumulation are likely to explain the wide range of overyielding and underyielding observed in diversity-productivity experiments (Hector et al. 2002, Kulmatiski et al., 2012).

PSFs have been suggested as a mechanism that can explain both underyielding and overyielding (Kulmatiski et al. 2012). PSF describes a process in which plants change soil conditions, which can then affect further plant growth (conspecific or heterospecific; Bever, 2003; Hamilton \& Frank, 2001; Wardle et al., 2004). These effects are often attributed to soil microbial communities (Ehrenfeld et al., 2005, Ke \& Wan, 2020, Reynolds et al. 2003), but they can also result from changes to soil chemistry (Ehrenfeld et al., 2005, Smith-Ramesh \& Reynolds, 2017), soil structure (Kyle et al., 2007), and soil animals (Eisenhauer et al., 2012).

Disease accumulation is one component of PSF that results in negative PSFs and can be expected to cause overyielding (Maron et al., 2011; Mommer et al., 2018; Schnitzer et al., 2011). Conversely, symbiont accumulation is another component of PSF, potentially resulting in a positive PSF. For example, a plant that accumulates species-specific symbionts can be expected to benefit more from those symbionts in a dense monoculture than in a diverse community (Kulmatiski et al. 2012). The role of plant mutualists in soil has been reported to affect plant community performance (Latz et al., 2012; Wagg et al., 2011) and suggested to co-determine selection and complementarity effects (Eisenhauer, 2011; Eisenhauer, Reich, \& Isbell, 2012). However, positive PSF can also occur when a species' growth is suppressed by soils cultivated by a different species (e.g., allelopathy; van der Putten et al., 2016). In either case, species with positive PSFs can be expected to be more productive in monoculture than in polyculture (i.e., they underyield; Kulmatiski et al., 2012).

While conceptually appealing, the magnitude of PSF effects in plant communities remains poorly understood for several reasons. Across the literature, roughly two-thirds of plants create negative PSFs, and one-third create positive PSFs (Cortois et al., 2016; Kulmatiski et al., 2008; Lekberg et al., 2018; van der Putten et al., 2016). However, most PSF research has been performed in the greenhouse and greenhouse-derived PSFs have been found to be larger than and uncorrelated with field-derived PSFs (Forero et al., 2019; Kulmatiski et al., 2008; Schittko et al., 2016). Further, most PSF research has measured PSFs without explicitly testing the role of the PSFs in plant mixtures (Ke \& Wan, 2020; Kulmatiski et al., 2012; van der Putten et al., 2013). As a result, it is not known if PSFs affect species coexistence or community productivity or if PSFs are overwhelmed by other factors related to plant growth such as competitive interactions, herbivory, or intrinsic growth rates (Heinze \& Joshi, 2018; Kulmatiski et al., 2011; Lekberg et al., 2018; Reinhart et al. 20218).

The overarching goal of this study was to test the role of PSFs in the diversity-productivity relationship. We established paired PSF and diversity-productivity experiments with mesic grassland species in Jena, Germany. Working in this site allowed us to test PSF effects in current and pre-existing diversity-productivity experiments (Roscher et al., 2016). We report PSF values and their relationship to competitive ability, but the emphasis of this paper was to test PSF effects during plant community establishment (i.e., plant growth during diversity-productivity experiments). To do this, a suite of plant community growth models 
was parameterized with (PSF) or without (Null) PSF data, and model predictions were compared to plant biomass in two and three-year-old plant communities. Consistent with modeling and greenhouse experiments, we predicted that PSFs effects would improve Null model predictions of plant community productivity because a) PSFs would be predominantly negative and explain overyielding, and b) positive PSFs would occur and contribute to underyielding (Maron et al. 2011; Schnitzer et al. 2011; Kulmatiski et al. 2012).

\section{Methods}

\section{Site}

In 2015, we established PSF and diversity-productivity experiments in the Jena Experiment field site on the floodplain of the Saale River, Jena, Germany with eutric fluvisols (5 - $33 \mathrm{~g} \mathrm{C} \mathrm{kg}^{-1}$ and $1.0-2.7 \mathrm{~g} \mathrm{~N} \mathrm{~kg}^{-1}$ soil; Roscher et al., 2004; Weisser et al., 2017). Long-term mean annual temperature and precipitation at the site are $9.8^{\circ} \mathrm{C}$ and $544 \mathrm{~mm}(2002-2018)$, respectively, and during the experiment (2015 - 2018) mean annual temperature and precipitation were $10.4^{\circ} \mathrm{C}$ and $499 \mathrm{~mm}$, respectively (Kolle, 2020). The first and last year of the experiment (2015 and 2018) were drier than average, $459 \mathrm{~mm}$ and $395 \mathrm{~mm}$, respectively, while 2017 was wetter than average $(615 \mathrm{~mm})$.

\section{Field Experiments}

The PSF experiment followed a two-phase, factorial bio-assay approach (Bever, 1994; Brinkman et al., 2010). This design is considered one of the most robust PSF experimental designs, because it measures plant growth in the field, on each soil type without mixing soils (Kulmatiski and Kardol 2008; Rinella and Reinhart 2018). In Phase I, monocultures of each plant species were grown for two years to create soils with a known plant cultivation history (nine soil treatments). Plants were then removed. In Phase 2, each plant species was grown for two years on replicate plots with each plant cultivation history (Bever, 1994; Brinkman et al., 2010; Rinella \& Reinhart, 2018). The diversity-productivity experiment, which we will refer to as the current diversity-productivity experiment, was designed to replicate the dominance experiment established at the study site in 2002 which we will refer to as the pre-existing experiment (Roscher et al., 2004). In both the current and pre-existing experiments, plant communities with 1,2, 3, 4, 6, and 9 species were grown for four years. Plant species included five grass species: Alopecurus pratensis, Arrhenatherum elatius, Dactylis glomerata, Phleum pratense, Poa trivialis; two tall herbs: Anthriscus sylvestris, Geranium pratense; and two legumes: Trifolium pratense, Trifolium repens(Roscher et al., 2004).

In Fall 2014, a 75 x 22 m area was mowed, sprayed with glyphosate herbicide (Roundup @ $0.045 \%$ v/v pelargonic acid; Evergreen Garden Care Österreich GmbH, Salzburg) and tilled using several passes to 30 $\mathrm{cm}$ with an agricultural cultivator. For the PSF experiment, a grid with 1,251 plots was created. To isolate each $35 \mathrm{~cm}$-wide by $75 \mathrm{~cm}$-long plot from each other, a $10 \mathrm{~cm}$-wide by $35 \mathrm{~cm}$-deep trench was dug around the outside of plots, and a custom-made, flat-bladed shovel was used to slice soils between plots to allow insertion of a $35 \mathrm{~cm}$ deep root barrier (RootBlock@ $1 \mathrm{~mm}$ high density polyethylene; GreenMax, Netherlands). Each of the nine target species was randomly assigned to 139 replicate plots. In March 2015, seeds $\left(4 \mathrm{~g} \mathrm{~m}^{-2}\right)$ were applied by hand for one species in each plot. Prior to seeding, seeds of Anthriscus sylvestris were stored at $-20{ }^{\circ} \mathrm{C}$ for two weeks (Roscher et al., 2004). Due to poor establishment, Anthriscus sylvestris and Geranium pratenseplots were reseeded in October 2015 with 2,000 germinating seeds $\left[7.5 \mathrm{~g} \mathrm{~m}^{-2}\right.$ and $28.3 \mathrm{~g}$

$\mathrm{m}^{-2}$, respectively; germination rates based on Roscher et al. (2004)]. Non-target species were removed by hand at least three times each growing season, and, consistent with other experiments at the site, aboveground biomass was harvested and removed each spring and fall as is typical for hay meadows in Central Europe (Roscher et al., 2004).

Phase 1 ended in September 2016, when standing biomass was removed and plots were treated with herbicide. Roughly two weeks later, plots were hand-tilled to prevent sprouting of Phase 1 species. Plots were randomly 
assigned so that each plant species was grown in 14 replicate plots that had grown the same species in Phase 1 (i.e., 'home' soils) and 15 replicate plots that had grown each of the other species in the experiment in Phase 1 (i.e., 'away' soils). Five replicate 'home' plots remained unseeded to assess the extent of resprouting growth in 'home' plots. It is important to distinguish new growth from resprouting, because resprouting growth would result in inappropriately positive PSF values. Mean resprouting growth varied in these control plots varied from 0 to $32 \mathrm{~g} \mathrm{~m}^{-2}$ and was removed from final biomass estimates in 'home' plots. On 15 March 2017, 2,000 pure live seeds $\mathrm{m}^{-2}$ were applied by hand to each PSF plot. In October 2017 and June-July 2018, biomass from Phase 2 plots was clipped to $5 \mathrm{~cm}$ above soil surface by hand, dried to constant weight at 70 ${ }^{\circ} \mathrm{C}$, and weighed.

The current diversity-productivity experiment included 223 plots $(1.5 \mathrm{~m}$ by $1.5 \mathrm{~m})$, also lined with root barriers. Monocultures were replicated three times ( 9 species x 3 replicates $=27$ plots). Each of the 91 plant communities grown in the pre-existing experiment was grown in one plot (91 plots; Supplemental materials; Roscher et al. 2004). Additionally, six randomly selected communities of two, three, four, and six species mixtures, were replicated in four additional plots $\left(4\right.$ species richness levels ${ }^{*} 6$ communities* 4 replicates $=96)$. Communities with all nine target species were replicated in nine plots. In March 2015, target seed mixtures with 2,000 pure live seeds per $\mathrm{m}^{2}$, equally distributed among species, were applied by hand to each plot. Again, aboveground biomass was clipped to $5 \mathrm{~cm}$ above soil surface in November 2015, June and October 2016 and 2017. A subsample of $0.1 \mathrm{~m}^{2}$ per plot was sorted by plant species, dried at $70^{\circ} \mathrm{C}$ for three days and weighed. As in the PSF experiment, non-target species were removed by hand at least three times per year from 2015-2017.

\section{Calculating Plant-Soil Feedbacks}

PSF data were primarily used to parameterize plant community models, but to provide values that are comparable to other studies, PSF values are reported. PSFs were calculated as the difference of growth on 'home' and 'away' soils divided by the maximum of 'home' and 'away' soils. Similar to the log response ratio, this calculation produces values bound by -1 and +1 , but these values are readily interpreted as the proportion of increased or decreased growth (Brinkman et al., 2010; Kulmatiski et al., 2012). Soil-level PSF values describe the growth of each plant species on each of eight 'away' soils resulting in 72 soil-level PSF values (i.e., eight values for each of nine species). Species-level PSF values describe the growth of each species across the other eight soil types resulting in nine PSF values. In both cases, PSF values and associated $95 \%$ confidence intervals were calculated using 2000 bootstrapped biomass on home and away samples (Schittko et al. 2016; Kulmatiski et al., 2017). PSF values with confidence intervals that do not overlap zero are considered positive or negative, as appropriate.

\section{Calculating Relative Competition Intensity (RCI)}

A goal of this research was to test whether or not PSFs improve predictions of plant growth in communities where other factors such as a plant's competitive ability are also important (Lekberg et al. 2018). To better understand how PSF may interact with a plant's competitive ability, we correlated PSFs with the relative competition index (RCI, Weigelt \& Jolliffe, 2003) where RCI = (monoculture biomass - twice the two-species mixture biomass)/monoculture biomass. A low RCI indicates higher biomass production of a species in twospecies mixtures than in monocultures (strong competitor). RCI was calculated for current and pre-existing diversity-productivity experiments.

\section{Simulating Plant Growth in Communities}

A suite of plant community growth models was parameterized with (PSF) or without (Null) PSF data (Kulmatiski et al., 2016). The models and modeling approach generally follow that of Kulmatiski et al. (2016), but briefly, the foundation of these models are logistic growth equations (equation 1). In addition to the effects of intrinsic plant growth rates $r$, total plant biomass in the community $\mathrm{P}$, and a carrying capacity 
$\mathrm{K}$, plant growth is also a function of soil conditions $\sigma$. Plants are assumed to change soil conditions as they grow, and plants grow at different rates on different soil conditions (Bever, 1994; Kulmatiski et al., 2011). In Null models, plant growth rates are the same across all soil conditions. Plants can 'compete' indirectly through carrying capacity, but competition coefficients were not included. Models were parameterized with different carrying capacities, data from different years (input data), and with different values for 'neutral' soils to produce a suite of simulations. Average biomass predictions from this suite of model parameterizations are reported. The goal of this modeling is to simulate relatively short-term plant growth in the field experiment and not to determine equilibrium species abundances (Kulmatiski et al. 2011; Feng et al. 2020).

In the PSF models, each plant species i conditions soil $j$, and therefore has a soil-specific growth rate $\mathrm{r}_{\mathrm{i}, \mathrm{j}}$. The biomass of plant species $\mathrm{i}$ at time $\mathrm{t}\left(\mathrm{P}_{\mathrm{i}, \mathrm{t}}\right)$, depends on its growth rate at $\mathrm{t}\left(\mathrm{r}_{\mathrm{i}, \mathrm{t}}\right)$ and is limited by either community-level carrying capacity $\mathrm{K}$ alone (equation 1 ) or additional species-level carrying capacity $x_{\mathrm{i}}$ (equation 2). At the community-level, $\mathrm{K}$ simulates interspecific competition, but 'competitive strength' is only defined by growth rates: $\mathrm{K}$ is defined as the maximum biomass a community can achieve. Whereas at the species-level, $x_{\mathrm{i}}$ simulates intraspecific competition: $x_{\mathrm{i}}$ is defined as the maximum biomass a species can achieve. The time- and plant-specific growth rate $r_{i, t}$ represent the summed product of soil-specific growth rates $r_{i, j}$ and the proportion of soil $\mathrm{j}$ at timet $\left(\sigma_{\mathrm{j}, \mathrm{t}}\right.$; equations 3 and 4$)$. Assuming gradual change of soil conditions as plants grow, we estimate growth rate on unconditioned soil ('neutral' growth rate, $\nu_{\mathrm{i}}$ ) and set the abundance of neutral soil to one $(100 \%)$ at $t=0$ (equation 3 ). While plants grow, neutral soil is subsequently replaced by conditioned soil.

\begin{tabular}{ll}
\hline $\mathrm{P}_{\mathrm{i}, \mathrm{t}+1}=\mathrm{P}_{\mathrm{i}, \mathrm{t}}+\mathrm{P}_{\mathrm{i}, \mathrm{t}} \mathrm{r}_{\mathrm{i}, \mathrm{t}}\left(1-\Sigma^{\mathrm{N}} \mathrm{i}_{\mathrm{l}=1} \mathrm{P}_{\mathrm{i}, \mathrm{t}} / \mathrm{K}\right) \mathrm{P}_{\mathrm{i}, \mathrm{t}+1}=\mathrm{P}_{\mathrm{i}, \mathrm{t}}+\mathrm{P}_{\mathrm{i}, \mathrm{t}} \mathrm{r}_{\mathrm{i}, \mathrm{t}}\left(1-\Sigma_{\mathrm{i}=1}^{\mathrm{N}} \mathrm{P}_{\mathrm{i}, \mathrm{t}} / \mathrm{K}-\mathrm{P}_{\mathrm{i}, \mathrm{t}} / x_{\mathrm{i}}\right)$ & equation 1 equation 2 \\
$\sigma_{\mathrm{j}, \mathrm{t}}=\mathrm{P}_{\mathrm{i}, \mathrm{t}} / \mathrm{K}$ & equation 3 \\
$\mathrm{r}_{\mathrm{i}, \mathrm{t}}=\Sigma_{\mathrm{i}=1}^{\mathrm{N}} \sigma_{\mathrm{i}, \mathrm{t}} \mathrm{r}_{\mathrm{i}, \mathrm{j}}+\left(1-\Sigma_{\mathrm{i}=1}^{\mathrm{N}} \sigma_{\mathrm{i}, \mathrm{t}}\right) \nu_{\mathrm{i}}$ & equation 4 \\
\hline
\end{tabular}

Growth rates on conditioned soil $\left(\mathrm{r}_{\mathrm{i}, \mathrm{j}}\right)$ were derived from plant biomass on PSF plots (input data) in 2017 and/or 2018 (Kulmatiski et al. 2011). 'Neutral' growth rates $\left(\nu_{\mathrm{i}}\right)$ were set to be growth rates on 'home', 'away', or across all PSF plots. Growth rates were calculated from final biomass on different soil types. For example for $\mathrm{P}_{\mathrm{i}, \mathrm{j}}, \mathrm{r}_{\mathrm{i}, \mathrm{t}}=\left(\mathrm{P}_{\mathrm{i}, \mathrm{j}} / \mathrm{P}_{0}\right)^{1 / \mathrm{T}}-1$, where $\mathrm{T}=52$ time steps, $\mathrm{P}_{0}=\mathrm{g} \mathrm{m}^{-2}$.

Two models (equation 1 or 2), three sources of input data (2017 only, 2018 only, or 2017 then 2018), and three 'neutral' growth rates (home, away, all plots) produced 18 Null and 18 PSF model simulations. Carrying capacities were defined as the mean \pm two standard deviations of total plant biomass $(\mathrm{K})$ in diversityproductivity plots or plant species biomass $(x)$ across all PSF plots. Models were run for three 52-time step iterations (t). To simulate harvest, each 53rd time step, plant biomass was set to $1 \%$ of $\mathrm{P}_{\mathrm{i}, \mathrm{t}}$. Simulations were performed in R (R Core Development Team, 2015).

\section{Dissecting Mechanisms Driving the Diversity-Productivity Relationship}

We estimated the net biodiversity effect based on calculations proposed by Loreau \& Hector (2001), which estimate the yield increase $\Delta \mathrm{Y}$ of a plant community compared to the combined performance of plant species in monocultures. We further used equations to partition the net biodiversity effect $(\Delta Y)$ into selection and complementarity effects (Loreau \& Hector, 2001).

\section{Statistics}

To describe species richness effects, we fit random intercept (linear mixed) and linear mixed models in $\mathrm{R}$ (R Core Development Team, 2015) using lme4 (Schielzeth \& Forstmeier, 2009; Bates et al, 2015; Schmid et al., 2017). Due to low establishment in 2015, we analyzed species biomass data by plot and year (i.e., the sum of spring and fall harvests as $\mathrm{g}$ dry mass $\mathrm{m}^{-2}$ ) for 2016 and 2017. Analyses followed those of Roscher et al. (2008) on the pre-existing diversity productivity experiment. The maximum likelihood method was 
used to find the 'best' random model among random intercepts such as species composition (com), year and their interaction (Roscher, Schumacher, Weisser et al., 2007; Roscher et al., 2008). The effects of block (soil gradient; Huston \& McBride, 2002; Weisser et al., 2017) and the interaction of block and Year (block:Year) were included as random intercepts for the pre-existing experiment, but not for the current experiment which was located in one area. From these random intercept models with no fixed effects, we extracted fixed effects of interest (Schmid et al., 2017). The contrast of monoculture and polyculture (MP) and the linear contrast of species richness (SR) were fixed effects $(\mathrm{MP}+\mathrm{SR})$. When analyzing mechanisms of the diversity-productivity relationship (selection and complementarity), the model was fit without the contrast of mono- and polycultures. Mixed models were fit with the maximum likelihood method to derive statistical significance of fixed effects from likelihood ratio tests $\left(X^{2}\right.$; Roscher et al., 2016). To avoid pseudoreplication, replicate plots were averaged prior to analyses so that the diversity productivity dataset had 300 samples (100 species compositions $\mathrm{x}$ three years). To compare species richness effects between experiments and simulations, a second random intercept model was used with the fixed effects model: data+SR+data:SR and random intercept model: com+com:Year where data is the data source (i.e., observed, PSF, or Null model predictions).

\section{Results}

\section{Plant-Soil Feedback}

At the species level (i.e., across soil types) there were six negative, one positive, and two neutral PSFs in 2017 (Fig. 1). The mean absolute value of species-level PSFs was 0.37 (the $95 \%$ confidence interval $\mathrm{CI}_{95}$ was 0.16 to 0.58 ). In other words, plants created soils that changed subsequent plant growth by $37 \%$. The arithmetic mean value of species-level PSF was -0.15 ( $\mathrm{CI}_{95}-0.50$ to 0.19$)$. In 2018, five species demonstrated a species-level (Fig. 1), though neither absolute (0.35) nor arithmetic (-0.17) PSF values differed between 2017 and $2018\left(\mathrm{t}_{\mathrm{abs}}=0.25 ; \mathrm{t}_{\mathrm{art}}=0.17 ; P>0.05, \mathrm{DF}=8\right.$; paired $t$-test; Fig. 1$)$.

At the soil-level, 27 of 72 PSFs were negative and eight were positive in 2017 (Fig. 2). The mean of absolute soil-level PSFs was $0.40\left(\mathrm{CI}_{95}=0.34\right.$ to 0.45$)$, while the arithmetic mean value was $-0.14\left(\mathrm{CI}_{95}=-0.24\right.$ to $-0.03)$. In 2018 , absolute values $\left(0.36, \mathrm{CI}_{95}=0.31\right.$ to 0.42$)$, and the arithmetic mean $\left(-0.15, \mathrm{CI}_{95}=-0.25\right.$ to $-0.05)$ were similar to and did not differ from 2017 values $\left(\mathrm{t}_{\mathrm{abs}}=1.50 ; \mathrm{t}_{\mathrm{art}}=0.44 ; P>0.05, \mathrm{df}=71 ;\right.$ paired t-test ) though only 13 of 72 soil-level PSFs differed from zero in 2018 (Fig. 2).

Competitive species demonstrated small PSF values and poor competitors demonstrated large positive or negative PSF values (Fig. 3). More specifically, RCI values from both the current and pre-existing experiments were correlated with absolute PSF values from 2017 (current: $\mathrm{F}_{1,134}=28.7, P<0.05, R=0.18$; pre-existing: $\mathrm{F}_{1,142}=29.0, P<0.001, R=0.17$ ) and 2018 (current: $\mathrm{F}_{1,134}=29.4 P<0.001, R=0.261$; pre-existing: $\mathrm{F}_{1,142}=50.06, P<0.05, R=0.18$; Fig. 3).

\section{Observed and Predicted Biodiversity Effects}

Polycultures produced $55 \%$ (current) and $40 \%$ (pre-existing) more biomass than monocultures, respectively (Fig. 4; Supplementary Table 1). In both experiments, selection effects were greater than complementarity effects (Fig. 4; Supplementary Table 1). Selection effects increased with species richness in the pre-existing experiments, but complementarity effects were unrelated to species richness in either experiment (Fig. 4; Supplementary Table 1). Between experiments, community biomass, net biodiversity and selection effects were greater in the current than pre-existing experiments. Complementarity effects were smaller in the current experiment than the pre-existing experiment (Fig. 4; Supplementary Table 1). Predictions of biodiversity effects never differed between PSF and Null models (Supplementary Table 2). Null and PSF model predictions did not differ from observed biomass or net biodiversity, but Null and PSF model predictions 
were smaller than selection effects and larger than complementarity effects in the current experiment (Fig. 4, Supplementary Table 2).

In regression analysis of community biomass, Null and PSF models explained $28 \%$ and $30 \%$, respectively of the variation in the current experiment and both explained $8 \%$ of variation in the pre-existing experiment (Supplementary Table 3). Similarly, for species biomass, Null and PSF models explained $42 \%$ and $40 \%$, respectively of the variation in the current experiment and $38 \%$ and $36 \%$, respectively of the variation in the pre-existing experiment.

\section{Predicted and Observed Species Abundance}

When present, A. elatius increased community biomass (Fig. 5; Supplementary Table 1). A. elatius represented more biomass $(90 \pm 10 \%)$ in the current than the pre-existing $(74 \pm 16 \%)$ experiments (Fig. 5). The second and third most abundant species both attained similar relative biomass in both experiments. $D$. glomerata represented $61 \pm 6 \%$ in the current experiment and $58 \pm 7 \%$ in the pre-existing experiment and this was greater than other species. Similarly, P. pratense represented $44 \pm 7 \%$ in the current experiment and $40 \pm 6 \%$ in the pre-existing experiment and that was more than other species (Fig. 5). Null and PSF models predicted $A$. elatius to be the dominant species (Supplementary Table 4, Fig. 5), contributing $62 \%$ ( \pm 17 $\%$; Null) and $64 \%$ ( $\pm 17 \%$; PSF), respectively, to community biomass. Because D. glomerata performed poorly in Phase 2, models underestimated its relative biomass with $23 \%( \pm 18 \%$; Null) and $19 \%( \pm 17$ $\%$; PSF) compared to observed communities. Thus, D. glomerata was replaced by P. pratense in simulated communities, contributing $56 \%$ ( $\pm 21 \%$; Null) and $55 \%$ ( $\pm 22 \%$; PSF) respectively, to community biomass compared to observations (current: $44 \% \pm 7 \%$; pre-existing: $40 \% \pm 6 \%$; Fig. 5).

\section{Discussion}

Because most PSF research continues to be performed on plant monocultures in greenhouse conditions, the extent to which PSFs affect plant communities in the field remains unclear (Crawford et al., 2019; Forero et al., 2019; Ke \& Wan, 2020; Reinhart et al. 2021). Our factorial experiment provided unusually comprehensive information about PSFs in the field. We measured all possible PSFs for nine species and found that plants, on average, created soils that changed subsequent plant growth by $36 \%$. However, because plants realized both positive and negative PSFs, the net effect was that plants grew $14 \%$ less on home than away soils. While most PSF studies simply measure PSFs, we also tested the effect of these PSFs in plant communities. Despite causing 36\% changes in plant biomass, PSFs had little effect on Null model predictions of plant community biomass across a range of species richness. While somewhat surprising, a lack of a PSF effect was appropriate in this site because species richness effects in this study were caused by selection effects and not complementarity effects (PSFs would appear as complementarity effects).

PSFs had little effect on Null model predictions for several reasons. First, even though the absolute value of PSFs was reasonably large, the net PSF effect was small because some PSFs were positive while others were negative. Second, PSFs for the two dominant plant species were small (-0.14 to 0.12). Third, because PSFs were, on average, smaller than differences in intrinsic growth rates (36\% versus 193\%), they were unlikely to change competitive outcomes between species (Kulmatiski 2016; Lekberg et al. 2018). Finally, A. elatius dominated across all species-richness levels so 'away' soils had little effect on A. elatius growth regardless of species richness. Broadly, our results demonstrated that large PSF values alone are not sufficient to explain plant species coexistence or the diversity productivity relationship at this site. In fact, overyielding at the site was caused primarily by selection effects, so complementarity effects of any kind (e.g., niche partitioning or PSF) were unimportant. Results do not exclude a role for PSF as a mechanism of species coexistence and productivity, particularly at other sites with larger complementarity effects, rather results highlight that PSF effects must be considered in the context of other factors affecting plant growth such as intrinsic growth rates (Crawford et al. 2019; Lekberg et al. 2019). 


\section{The Curious Case of Plant-Soil Feedbacks and the Dominant Species}

We predicted that negative PSFs would cause overyielding because soil pathogens would be 'diluted' in diverse communities relative to monocultures (Kulmatiski et al., 2012; Maron et al., 2011; Schnitzer et al., 2011). However, A. elatius was such a dominant species that it maintained at least $75 \%$ relative biomass across all species-richness levels in the current diversity-productivity experiment. From a PSF perspective, an important consequence of this dominance is that A. elatius effectively only grew on 'home' soils. Therefore, A. elatius never benefited from pathogen dilution on 'away' soils. Research examining potential PSF effects 'in vitro' often assume that species are competitively equivalent (Bever et al 2003; Kulmatiski et al. 2011). Performing this experiment in field conditions helps refocus the role of PSF in the context of strong competitive imbalances among species which are common in field conditions (Crawford et al. 2019; Lekberg et al. 2018).

\section{Are Neutral PSFs a Successful Strategy?}

In addition to primarily growing on 'self' soils, the dominant speciesA. elatius realized a small PSF with little variability within or across soil treatments (Fig. 2). It is possible that small PSFs and small variability covary. It is reasonable to expect that, for a plant species to dominate in many communities, it will grow well across soil treatments and, therefore, demonstrate small and consistent PSFs. In contrast, plant species with large positive PSFs may have difficulty establishing in 'away' soils, while species with a large negative PSF may have difficulty attaining large growth on 'home' soils (Levine et al., 2006). Our results suggest that there may be a selective pressure to maintain neutral PSFs with low variability to dominate plant communities. Consistent with this idea, we found that competitive species were associated with small PSF values (Fig. 3) while sub-dominant species demonstrated large positive and large negative PSF. This perspective may help explain why PSFs often show weak correlations with landscape abundance (Reinhart et al. 2021, but see Mangan et al. 2010; Kulmatiski et al. 2017).

There is also a statistical reason that dominant species may demonstrate small PSFs. It is more likely that plant species with small growth will realize large proportional changes in growth (Pfisterer \& Schmid, 2002). For example, a plant species that can grow to $50 \mathrm{~g} \mathrm{~m}^{-2}$ on 'home' soils can easily be imagined growing to 0 or $200 \mathrm{~g} \mathrm{~m}^{-2}$ on 'away' soils, resulting in PSFs of 1.0 and -0.75 , respectively. However, it is essentially impossible for plant species to grow to $1,000 \mathrm{~g} \mathrm{~m}^{-2}$ on 'home' soils and 4,000 $\mathrm{g} \mathrm{m}^{-2}$ on 'away' soils because $4,000 \mathrm{~g} \mathrm{~m}^{-2}$ is beyond carrying capacity in grasslands. As a result, subdominant species are more likely to have large PSFs than dominant species. We are not aware of other studies suggesting these ideas and this is likely because PSF experiments rarely perform the types of large factorial experiments needed to examine PSFs for many species across soil types (Rinella and Reinhart 2018).

\section{Diversity-Productivity Relationships}

Species richness effects were similar to other biodiversity experiments in more mesic sites (Cardinale et al., 2011; Hector et al., 1999). However, the mechanisms driving this response differed between the current and pre-existing experiments. In the pre-existing experiment, polyculture biomass was driven by selection (21\% of monoculture biomass) and complementarity (14\%) effects. In the current experiment, overyielding was largely explained by selection effects (43\%) and countered by negative complementarity effects (-20\%). A. elatiuswas more dominant in the current than the pre-existing experiment (Fig. 5; Clark et al. 2020). Community productivity in the Jena Experiment varies widely among years due to different environmental conditions (Weisser et al., 2017), so it is likely that climate or other environmental conditions that differed between the two studies also caused greater dominance effects in the current experiment (Marquard et al., 2009; Guimarães-Steinicke et al., 2019). For example, a large flooding event in 2013 may have increased $A$. elatius growth by increasing nutrient availability (Wright et al., 2015). A. elatius is strongly competitive for light and nitrogen, so greater seeding rates in the current experiment may have exaggerated asymmetric 
competitive effects (Lorentzen et al. 2008; Roscher et al. 2008). It is interesting to note, that even though the mechanisms differed, the net biodiversity effect was similar in the new and old experiments.

\section{Species-Level vs. Soil-Level PSFs}

Because sample sizes increase exponentially as species are added to factorial PSF-experiments, most studies measure PSFs for one to a few target species (Smith-Ramesh \& Reynolds, 2017; Van der Putten et al., 2013). By measuring all 72 potential PSFs for nine species, this study provided unusually comprehensive insights into how PSFs vary among soil conditioned by different species. For the most part, PSFs were consistent among soil treatments. It is not unreasonable to expect PSFs to vary widely across differently conditioned soils (Bezemer et al., 2006; Rinella \& Reinhart, 2018; Smith-Ramesh \& Reynolds, 2017). For example, a plant species may grow well on a soil conditioned by a N-fixing species and poorly on a soil conditioned by an early-successional species that accumulated a large pool of generalist soil pathogens (Chapin et al., 1994; Van der Putten et al., 2013). However, we observed only one species that had a positive PSF on one soil treatment and a negative PSF on another soil treatment ( $P$. pratense). The fact that PSF values were consistent across soil treatments suggests that PSFs in this system are determined primarily by growth on 'home' soil.

\section{Site Differences}

It has been suggested that PSFs will intensify competitive effects in nutrient-rich conditions and strengthen facilitative effects in nutrient-poor conditions (Bever, 2003; Lekberg et al., 2018). Consistent with this idea, we found that PSFs were more negative, and competitive effects (selection effects) were larger in the current experiment, performed at a mesic, nutrient-rich site relative to a similar recent study performed at a drier and nutrient-poor site (Forero 2021). Both absolute (0.36 vs 0.27 ) and net (-0.14 vs. 0.10) PSFs were larger at the nutrient-rich vs. nutrient-poor site, respectively (Forero 2020). Further, overyielding was smaller at the nutrient-rich site than the nutrient-poor site (Craven et al. 2016; Forero 2021). Larger PSFs and competitive effects in nutrient-rich conditions provide a potential explanation for why the strength and trajectory of biodiversity-ecosystem functioning relationships over time differ between more and less fertile soils (Eisenhauer et al., 2019; Guerrero-Ramirez et al., 2019; Ratcliffe et al., 2017).

\section{Conclusion}

To affect species coexistence, or to have large effects on plant community productivity, PSFs must be large relative to differences in intrinsic growth rates among species (Crawford et al., 2019; Ke \& Wan, 2020; Lekberg et al., 2018). While PSFs changed plant growth within plant species by $36 \%$, this effect was smaller than differences in growth among species, and the dominant plant species demonstrated small PSFs in our experiment. The lack of an effect of PSFs of the magnitude observed were surprising, but appropriate because complementarity effects did not contribute to overyielding observed in the current diversity productivity experiment. Our results demonstrate that species identity and composition of the plant communities can determine whether PSFs are important to plant community growth: large PSFs for sub-dominant species and small PSFs for dominant species will cause small overall effects on plant community productivity. Our results also highlight a potential connection between PSFs and competitive ability (Lekberg et al., 2018; Petermann et al., 2008). More specifically, there may be selective pressure for species to produce both small PSFs and large competitive ability in order to dominate. Results provide an important but uncommon perspective on the role of PSF in plant communities in field conditions. 


\section{Acknowledgements}

Research was funded by United States National Science Foundation Award \#1354129. The team of the Jena-Experiment provided field space and infrastructure to successfully perform our experiments. Gerlinde Kratsch, Ulrike Gudd and the gardeners of the Jena Experiment, Steffen, Katja, Heike, Ute, and Silke were highly supportive at the field site. Carsten Moeller co-managed the field site over the course of the experiment and provided labor, advice, and passion. Oak Rankin and Robert Hicks and Larry Broom helped install the experiment. The Jena Experiment is funded by the Deutsche Forschungsgemeinschaft (DFG, German Research Foundation, FOR 1451 and FOR 5000). NE acknowledges support from the German Centre for Integrative Biodiversity Research (iDiv) Halle-Jena-Leipzig, funded by the German Research Foundation (FZT 118). This research was supported by the Utah Agricultural Experiment Station, Utah State University, and approved as journal paper number 9433. The authors have no conflict of interest to state.

\section{Author's contribution}

AK, JN designed the Experiment, JG, AK and LF installed and managed the experiment. JG managed and performed data collection. JG and AK analyzed and summarized data. NE and AE contributed organizational expertise, lab infrastructure, and equipment to process samples. All authors contributed to the concept, structure, and interpretation in this manuscript.

\section{Data accessibility}

Upon acceptance, all data used in this manuscript will be made publicly available with a permanent doi at the USU Digital commons (https://digitalcommons.usu.edu/).

\section{References}

Barry, K. E., Mommer, L., van Ruijven, J., Wirth, C., Wright, A. J., Bai, Y., .. Weigelt, A. (2019). The Future of Complementarity: Disentangling Causes from Consequences. Trends in Ecology and Evolution, Vol. 34, pp. 167-180. Elsevier Ltd. doi: 10.1016/j.tree.2018.10.013

Bates, D., Machler, M., Bolker, B. M., \& Walker, S. C. (2015). Fitting linear mixed-effects models using lme4. Journal of Statistical Software, 67 (1), 1-48. doi: 10.18637/jss.v067.i01

Bever, J. D. (1994). Feedback between plants and their soil communities in an old field community. Ecology , 75 (7), 1965-1977. doi: 10.2307/1941601

Bever, J. D. (2003). Soil community feedback and the coexistence of competitors: Conceptual frameworks and empirical tests. New Phytologist, Vol. 157, pp. 465-473. John Wiley \& Sons, Ltd. doi: 10.1046/j.14698137.2003.00714.x

Bezemer, T. M., Lawson, C. S., Hedlund, K., Edwards, A. R., Brook, A. J., Igual, J. M., ... Van Der Putten, W. H. (2006). Plant species and functional group effects on abiotic and microbial soil properties and plant-soil feedback responses in two grasslands. Journal of Ecology , 94 (5), 893-904. doi: 10.1111/j.13652745.2006.01158.x

Brinkman, E. P., Van der Putten, W. H., Bakker, E. J., \& Verhoeven, K. J. F. (2010). Plant-soil feedback: Experimental approaches, statistical analyses and ecological interpretations. Journal of Ecology ,98 (5), 1063-1073. doi: 10.1111/j.1365-2745.2010.01695.x 
Cardinale, B. J., Matulich, K. L., Hooper, D. U., Byrnes, J. E., Duffy, E., Gamfeldt, L., .. Gonzalez, A. (2011). The functional role of producer diversity in ecosystems. American Journal of Botany ,98 (3), 572-592. doi: $10.3732 /$ ajb.1000364

Chapin, F. S. I. I., Walker, L. R., Fastie, C. L., \& Sharman, L. C. (1994). Mechanisms of primary succession following deglaciation at Glacier Bay, Alaska. Ecological Monographs , 64 (2), 149-175. doi: 10.2307/2937039

Cortois, R., Schroder-Georgi, T., Weigelt, A., Putten, W. H., \& De Deyn, G. B. (2016). Plant-soil feedbacks: role of plant functional group and plant traits. Journal of Ecology , 104 (6), 1608-1617. doi: 10.1111/13652745.12643

Craven, D., Isbell, F., Manning, P., Connolly, J., Bruelheide, H., Ebeling, A., Roscher, C., Van Ruijven, J., Weigelt, A., Wilsey, B. and Beierkuhnlein, C. (2016). Plant diversity effects on grassland productivity are robust to both nutrient enrichment and drought.Philosophical Transactions of the Royal Society B: Biological Sciences, 371 (1694), 20150277.

Crawford, K. M., Bauer, J. T., Comita, L. S., Eppinga, M. B., Johnson, D. J., Mangan, S. A., ... Bever, J. D. (2019). When and where plant-soil feedback may promote plant coexistence: a meta-analysis.Ecology Letters , 22 (8), ele.13278. doi: 10.1111/ele.13278

Ehrenfeld, J. G., Ravit, B., \& Elgersma, K. (2005, October 25). Feedback in the plant-soil system. Annual Review of Environment and Resources, Vol. 30, pp. 75-115. Annual Reviews. doi: 10.1146/annurev.energy.30.050504.144212

Eisenhauer, N. (2011). Aboveground-belowground interactions as a source of complementarity effects in biodiversity experiments. Plant and Soil , 351 (1-2), 1-22. doi: 10.1007/s11104-011-1027-0

Eisenhauer, N., Reich, P. B., \& Isbell, F. (2012). Decomposer diversity and identity influence plant diversity effects on ecosystem functioning.Ecology , 93 (10), 2227-2240. doi: 10.1890/11-2266.1

Eisenhauer, N., Reich, P. B., \& Scheu, S. (2012). Increasing plant diversity effects on productivity with time due to delayed soil biota effects on plants. Basic and Applied Ecology , 13 (7), 571-578. doi: 10.1016/j.baae.2012.09.002

Eisenhauer, N., Schielzeth, H., Barnes, A. D., Barry, K. E., Bonn, A., Brose, U., .. Jochum, M. (2019). A multitrophic perspective on biodiversity-ecosystem functioning research. In Advances in Ecological Research (Vol. 61, pp. 1-54). Academic Press Inc. doi: 10.1016/bs.aecr.2019.06.001

Feng, Y., Soliveres, S., Allan, E., Rosenbaum, B., Wagg, C., Tabi, A., De Luca, E., Eisenhauer, N., Schmid, B., Weigelt, A. and Weisser, W.W. (2020). Inferring competitive outcomes, ranks and intransitivity from empirical data: A comparison of different methods. Methods in Ecology and Evolution, 11 (1) 117-128. doi: 10.1111/2041-210X.13326

Forero, L. E., Grenzer, J., Heinze, J., Schittko, C., \& Kulmatiski, A. (2019). Greenhouse- and FieldMeasured Plant-Soil Feedbacks Are Not Correlated. Frontiers in Environmental Science, 7 . doi: 10.3389 /fenvs.2019.00184

Forero, L.E. (2021) "Mechanisms of Overyielding and Coexistence in Diverse Tallgrass Prairie Communities". Utah State University Dissertations . https://digitalcommons.usu.edu/etd/8018

Guerrero-Ramirez, N. R., Reich, P. B., Wagg, C., Ciobanu, M., \& Eisenhauer, N. (2019). Diversity-dependent plant-soil feedbacks underlie long-term plant diversity effects on primary productivity.Ecosphere , 10 (4), e02704. doi: 10.1002/ecs2.2704

Guimaraes-Steinicke, C., Weigelt, A., Ebeling, A., Eisenhauer, N., Duque-Lazo, J., Reu, B., ... Wirth, C. (2019). Terrestrial laser scanning reveals temporal changes in biodiversity mechanisms driving grassland productivity. In Advances in Ecological Research (Vol. 61, pp. 133-161). Academic Press Inc. doi: 10.1016/bs.aecr.2019.06.003 
Hamilton, E. W., \& Frank, D. A. (2001). Can Plants Stimulate Soil Microbes and Their Own Nutrient Supply? Evidence from a Grazing Tolerant Grass. Ecology , 82 (9), 2397. doi: 10.2307/2679923

Hector, A., Schmid, B., Beierkuhnlein, C., Caldeira, M. C., Diemer, M., Dimitrakopoulos, P. G., Lawton, J. H. (1999). Plant Diversity and Productivity Experiments in European Grasslands. Science ,286 (5442), 1123-1127. doi: 10.1126 /science.286.5442.1123

Heinze, J., \& Joshi, J. (2018). Plant-soil feedback effects can be masked by aboveground herbivory under natural field conditions.Oecologia , 186 (1), 235-246. doi: 10.1007/s00442-017-3997-y

Huston, M. A., \& McBride, A. C. (2002). Evaluating the relative strengths of biotic versus abiotic controls on ecosystem processes. In Michel Loreau, S. Naeem, \& P. Inchausti (Eds.), Biodiversity and Ecosystem functioning: synthesis and Perspectives (pp. 47-60). Oxford: Oxford University Press.

Ke, P. J., \& Wan, J. (2020). Effects of soil microbes on plant competition: a perspective from modern coexistence theory.Ecological Monographs . doi: 10.1002/ecm.1391

Kolle, O. (2020). Weather Station Saaleaue. Retrieved from Max-Planck Institut fur Biogeochemie, Jena website: https://www.bgc-jena.mpg.de/wetter/

Kulmatiski, A., Beard, K.H., Norton, J.M., Heavilin, J.E., Forero, L.E. and Grenzer, J. (2017). Live long and prosper: plant-soil feedback, lifespan, and landscape abundance covary. Ecology, 98 (12) 3063-3073.

Kulmatiski, A., Beard, K. H., Grenzer, J., Forero, L., \& Heavilin, J. (2016). Using plant-soil feedbacks to predict plant biomass in diverse communities. Ecology , 97 (8). doi: 10.1890/15-2037.1

Kulmatiski, A., Beard, K. H., \& Heavilin, J. (2012). Plant-soil feedbacks provide an additional explanation for diversity-productivity relationships. Proceedings of the Royal Society B: Biological Sciences , 279 (1740), 3020-3026. doi: 10.1098/rspb.2012.0285

Kulmatiski, A., Heavilin, J., \& Beard, K. H. (2011). Testing predictions of a three-species plant-soil feedback model. Journal of Ecology , 99 (2), 542-550. doi: 10.1111/j.1365-2745.2010.01784.x

Kulmatiski, A., Beard, K. H., Stevens, J. R., \& Cobbold, S. M. (2008). Plant-soil feedbacks: A metaanalytical review. Ecology Letters, Vol. 11, pp. 980-992. doi: 10.1111/j.1461-0248.2008.01209.x

Kulmatiski, A. and Kardol, P. (2008). Getting plant-soil feedbacks out of the greenhouse: experimental and conceptual approaches. InProgress in botany (449-472). Springer, Berlin, Heidelberg.

Kyle, G. P., Beard, K. H., \& Kulmatiski, A. (2007). Reduced soil compaction enhances establishment of non-native plant species.Plant Ecology , 193 (2), 223-232. doi: 10.1007/s11258-006-9260-y

Latz, E., Eisenhauer, N., Rall, B. C., Allan, E., Roscher, C., Scheu, S., \& Jousset, A. (2012). Plant diversity improves protection against soil-borne pathogens by fostering antagonistic bacterial communities. Journal of Ecology , 100 (3), 597-604. doi: 10.1111/j.1365-2745.2011.01940.x

Lekberg, Y., Bever, J. D., Bunn, R. A., Callaway, R. M., Hart, M. M., Kivlin, S. N., .. van der Putten, W. H. (2018, August 1). Relative importance of competition and plant-soil feedback, their synergy, context dependency and implications for coexistence. Ecology Letters, Vol. 21, pp. 1268-1281. Blackwell Publishing Ltd. doi: 10.1111/ele.13093

Levine, J. M., Pachepsky, E., Kendall, B. E., Yelenik, S. G., \& Lambers, J. H. R. (2006, September 1). Plant-soil feedbacks and invasive spread. Ecology Letters, Vol. 9, pp. 1005-1014. John Wiley \& Sons, Ltd. doi: $10.1111 / \mathrm{j} .1461-0248.2006 .00949 . x$

Loreau, M, \& Hector, A. (2001). Partitioning selection and complementarity in biodiversity experiments. Nature ,412 (6842), 72-76. doi: 10.1038/35083573 
Loreau, M, Naeem, S., Inchausti, P., Bengtsson, J., Hector, A., Hooper, D. U., .. Schmid, B. (2001). Biodiversity and ecosystem functioning: current knowledge and future challenges. Science ,294 (5543), 804-808. Retrieved from http://dx.doi.org/10.1126/science.1064088

Lorentzen, S., Roscher, C., Schumacher, J., Schulze, E. D., \& Schmid, B. (2008). Species richness and identity affect the use of aboveground space in experimental grasslands. Perspectives in Plant Ecology, Evolution and Systematics , 10 (2), 73-87. doi: 10.1016/j.ppees.2007.12.001

Mangan, S.A., Schnitzer, S.A., Herre, E.A., Mack, K.M., Valencia, M.C., Sanchez, E.I. and Bever, J.D. (2010). Negative plant-soil feedback predicts tree-species relative abundance in a tropical forest.Nature, 466 (7307),752-755.

Maron, J. L., Marler, M., Klironomos, J. N., \& Cleveland, C.C. (2011). Soil fungal pathogens and the relationship between plant diversity and productivity. Ecology Letters , 14 (1), 36-41. doi: 10.1111/j.14610248.2010.01547.x

Marquard, E., Weigelt, A., Temperton, V. M., Roscher, C., Schumacher, J., Buchmann, N., ... Schmid, B. (2009). Plant species richness and functional composition drive overyielding in a six-year grassland experiment. Ecology , 90 (12), 3290-3302. doi: 10.1890/09-0069.1

Mommer, L., Cotton, T. E. A., Raaijmakers, J. M., Termorshuizen, A. J., van Ruijven, J., Hendriks, M., ... Dumbrell, A. J. (2018). Lost in diversity: the interactions between soil-borne fungi, biodiversity and plant productivity. New Phytologist, 218 (2), 542-553. doi: 10.1111/nph.15036

Petermann, J. S., Fergus, A. J. F. F., Turnbull, L. A., \& Schmid, B. (2008). Janzen-Connell effects are widespread and strong enough to maintain diversity in grasslands. Ecology , 89 (9), 2399-2406. doi: $10.1890 / 07-2056.1$

Pfisterer, A. B., \& Schmid, B. (2002). Diversity-dependent production can decrease the stability of ecosystem functioning. Nature , 416 (6876), 84-86. doi: 10.1038/416084a

R Core Development Team. (2015). R: a language and environment for statistical computing, 3.2.1. Document Freely Available on the Internet at: Http://Www. r-Project. Org . Vienna, Austria: R Foundation for Statistical Computing. doi: 10.1017/CBO9781107415324.004

Reinhart, K.O., Bauer, J.T., McCarthy-Neumann, S., MacDougall, A.S., Hierro, J.L., Chiuffo, M.C., Mangan, S.A., Heinze, J., Bergmann, J., Joshi, J. and Duncan, R.P., Diez, J.M., Kardol, P., Rutten, G., Fischer, M., van der Putten W.H., Bezemer, T.M. and Klironomos, J. (2021). Globally, plant-soil feedbacks are weak predictors of plant abundance.Ecology and Evolution . doi: 10.1002/ece3.7167

Reynolds, H. L., Packer, A., Bever, J. D., \& Clay, K. (2003). Grassroots ecology: Plant-microbe-soil interactions as drivers of plant community structure and dynamics. Ecology, Vol. 84, pp. 2281-2291. Ecological Society of America. doi: 10.1890/02-0298

Rinella, M. J., \& Reinhart, K. O. (2018). Toward more robust plant-soil feedback research. Ecology , 99 (3), 550-556. doi: 10.1002/ecy.2146

Roscher, C., Schmid, B., Kolle, O., \& Schulze, E. D. (2016). Complementarity among four highly productive grassland species depends on resource availability. Oecologia , 181 (2), 571-582. doi: 10.1007/s00442-016$3587-4$

Roscher, C., Schumacher, J., Baade, J., Wilcke, W., Gleixner, G., Weisser, W. W., .. Geographie, I. (2004). The role of biodiversity for element cycling and trophic interactions: an experimental approach in a grassland community. Basic and Applied Ecology , 5 (2), 107-121. doi: 10.1078/1439-1791-00216

Roscher, C., Thein, S., Schmid, B., \& Scherer-lorenzen, M. (2008). Complementary nitrogen use among potentially dominant species in a biodiversity experiment varies between two years. Journal of Ecology , 96 (3), 477-488. doi: 10.1111/j.1365-2745.2008.01353.x 
Schielzeth, H., \& Forstmeier, W. (2009). Conclusions beyond support: Overconfident estimates in mixed models. Behavioral Ecology ,20 (2), 416-420. doi: 10.1093/beheco/arn145

Schittko, C., Runge, C., Strupp, M., Wolff, S., \& Wurst, S. (2016). No evidence that plant-soil feedback effects of native and invasive plant species under glasshouse conditions are reflected in the field.Journal of Ecology , 104 (5), 1243-1249. doi: 10.1111/1365-2745.12603

Schmid, B., Baruffol, M., Wang, Z., \& Niklaus, P. A. (2017). A guide to analyzing biodiversity experiments. Journal of Plant Ecology ,10 (1), 91-110. doi: 10.1093/jpe/rtw107

Schnitzer, S. A., Klironomos, J. N., Hillerislambers, J., Kinkel, L. L., Reich, P. B., Xiao, K., .. Scheffer, M. (2011). Soil microbes drive the classic plant diversity-productivity pattern. Ecology ,92 (2), 296-303. doi: $10.1890 / 10-0773.1$

Smith-Ramesh, L. M., \& Reynolds, H. L. (2017). The next frontier of plant-soil feedback research: unraveling context dependence across biotic and abiotic gradients. Journal of Vegetation Science ,28 (3), 484-494. doi: $10.1111 /$ jvs. 12519

Tilman, D., Lehman, C. L., \& Thomson, K. T. (1997). Plant diversity and ecosystem productivity: Theoretical considerations. Proceedings of the National Academy of Sciences of the United States of America,94 , 1857-1861. doi: 10.1073/pnas.94.5.1857

Tilman, D., Reich, P. B., Knops, J., Wedin, D., Mielke, T., \& Lehman, C. (2001). Diversity and productivity in a long-term grassland experiment. Science , 294 (5543), 843-845. doi: 10.1126/science.1060391

van der Putten, W. H., Bardgett, R. D., Bever, J. D., Bezemer, T. M., Casper, B. B., Fukami, T., ... Wardle, D. A. (2013). Plant-soil feedbacks: The past, the present and future challenges. Journal of Ecology , 101 (2), 265-276. doi: 10.1111/1365-2745.12054

van der Putten, W. H., Bradford, M. A., Pernilla Brinkman, E., van de Voorde, T. F. J., \& Veen, G. F. (2016). Where, when and how plant-soil feedback matters in a changing world. Functional Ecology,30 (7), 1109-1121. doi: 10.1111/1365-2435.12657

Wagg, C., Jansa, J., Schmid, B., \& van der Heijden, M. G. A. a. (2011). Belowground biodiversity effects of plant symbionts support aboveground productivity. Ecology Letters , 14 (10), 1001-1009. doi: 10.1111/j.1461-0248.2011.01666.x

Wardle, D. a, Bardgett, R. D., Klironomos, J. N., Setala, H., van der Putten, W. H., \& Wall, D. H. (2004). Ecological linkages between aboveground and belowground biota. Science (New York, N.Y.) ,304 (5677), 1629-1633. doi: 10.1126/science.1094875

Weigelt, A., Ebeling, A., Roscher, C., Temperton, V., De Luca, E., Wagg, C., .. Meyer, S. T. (2016). Collection of aboveground community and species-specific plant biomass from the Jena Experiment (time series since 2002). PANGAEA. doi: 10.1594/PANGAEA.866358

Weigelt, A., \& Jolliffe, P. (2003, October 1). Indices of plant competition. Journal of Ecology, Vol. 91, pp. 707-720. John Wiley \& Sons, Ltd. doi: 10.1046/j.1365-2745.2003.00805.x

Weisser, W. W., Roscher, C., Meyer, S. T., Ebeling, A., Luo, G., Allan, E., ... Eisenhauer, N. (2017). Biodiversity effects on ecosystem functioning in a 15-year grassland experiment: Patterns, mechanisms, and open questions. Basic and Applied Ecology , 23 , 1-73. doi: 10.1016/j.baae.2017.06.002

Wright, A. J., Ebeling, A., De Kroon, H., Roscher, C., Weigelt, A., Buchmann, N., ... Eisenhauer, N. (2015). Flooding disturbances increase resource availability and productivity but reduce stability in diverse plant communities. Nature Communications , 6 (1), 1-6. doi: 10.1038/ncomms7092 


\section{Figures}

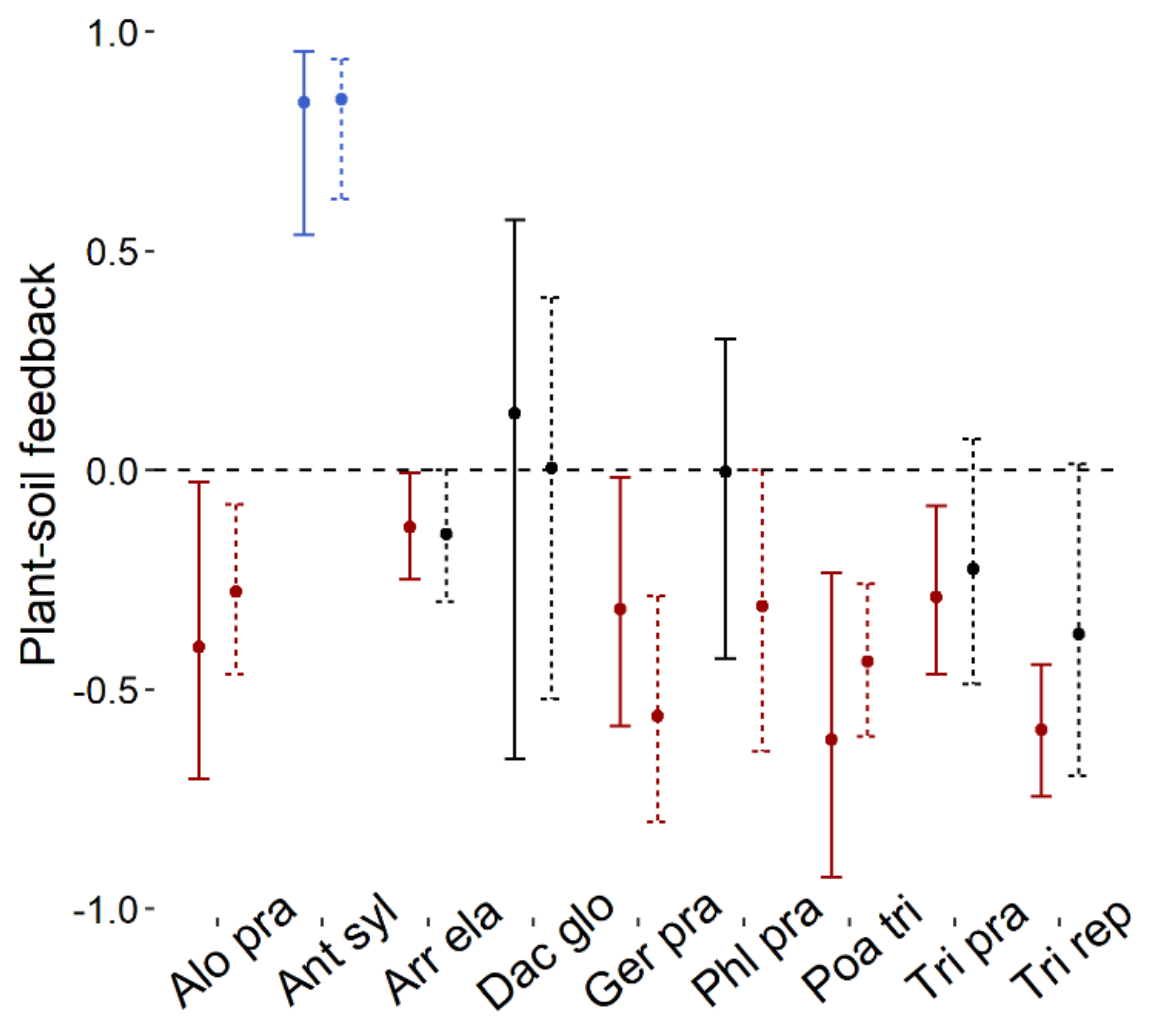

Fig. 1 Species-level plant-soil feedback (PSF) for nine grassland species, Jena, Germany. Values represent the mean and variation in PSF observed across the eight other soil types in the experiment. Positive values indicate the proportion to which a plant grows better on 'home' than 'away' soils. Negative values indicate the proportion to which a plant grows better on 'away' than 'home' soils. Solid and dotted lines are from fall 2017 and fall 2018, respectively. Error bars represent 95\% confidence intervals from bootstrapped values. Red, black and blue values represent negative, neutral and positive PSFs, respectively. Species abbreviations on the X-axis: five grass species: Alopecurus pratensis (Alo pra), Arrhenatherum elatius (Arr ela), Dactylis glomerata (Dac glo), Phleum pratense (Phl pra), Poa trivialis (Poa tri); two tall herbs: Anthriscus sylvestris (Ant syl), Geranium pratense(Ger pra); and two legumes: Trifolium pratense (Tri pra), Trifolium repens (Tri rep). 


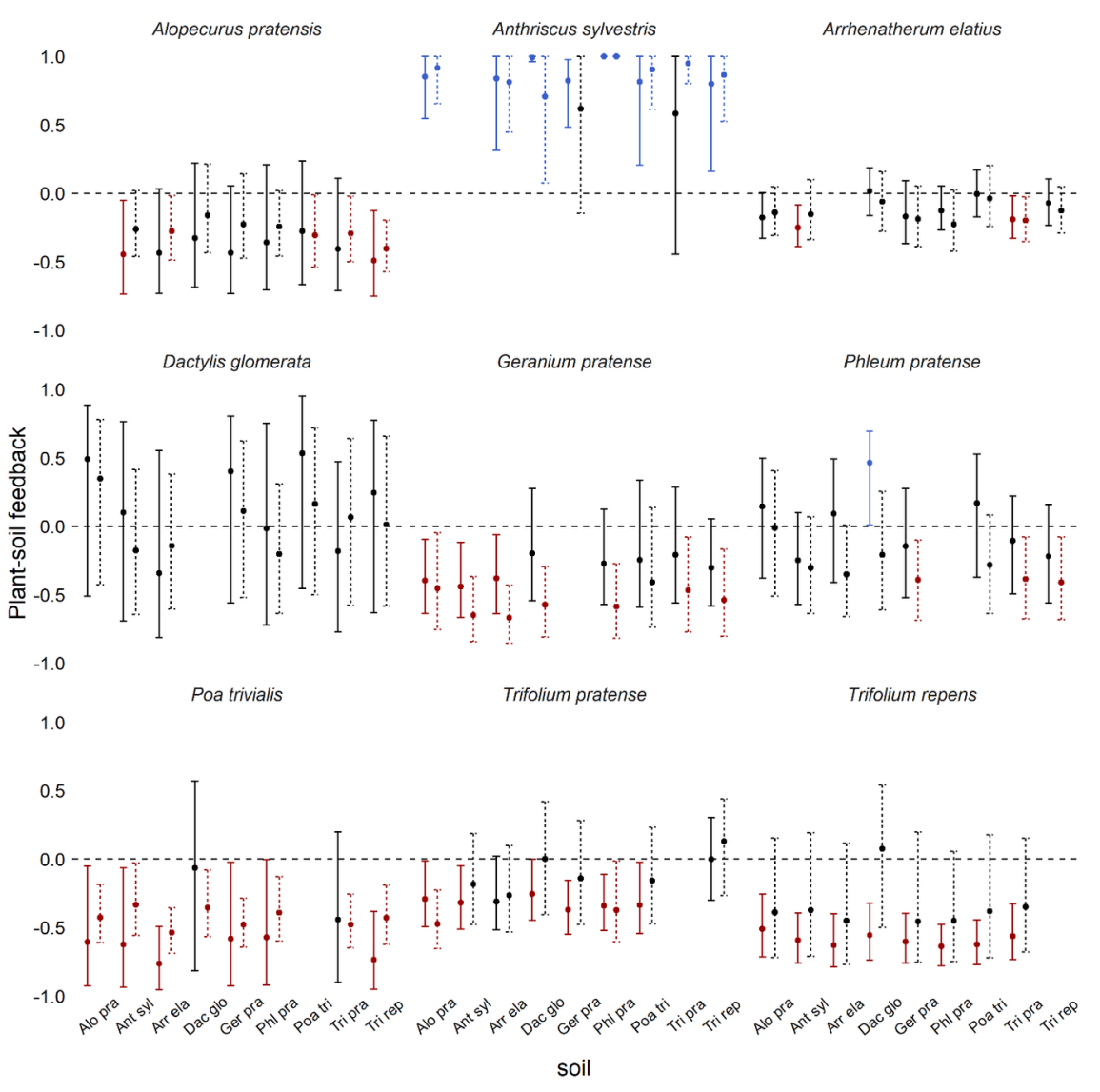

Fig. 2 Soil-level plant-soil feedback (PSF). Each panel shows the PSFs for a plant species across eight soil types. Soil types are defined by the plant species that cultivated them. Solid and dotted lines are from fall 2017 and fall 2018, respectively. Each value derived from target plant biomass in 14 plots with 'home' soils and 15 plots with 'away' soils. Error bars represent $95 \%$ confidence intervals of bootstrapped values. Red, black and blue values represent negative, neutral and positive PSFs, respectively. Species abbreviations listed in Fig. 1. 


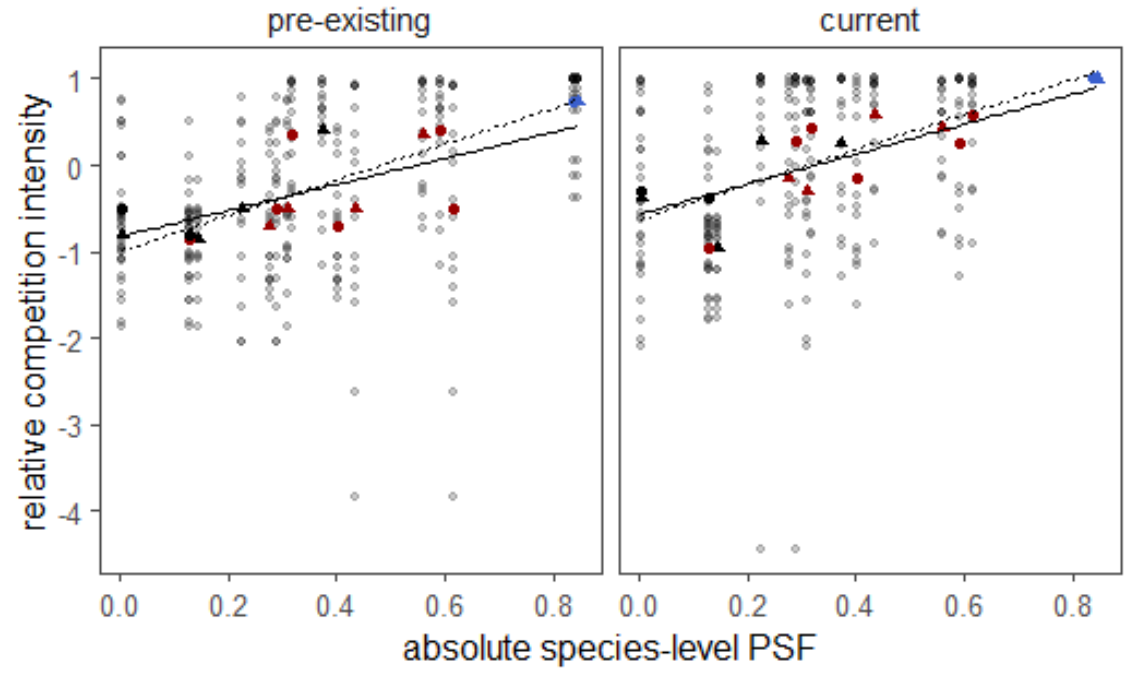

Fig. 3 Correlation of the absolute value of species-level plant-soil feedback (PSF) and relative competition intensity (RCI). The positive slope indicated that competitive species were associated with small PSF values and poor competitors were associated with large PSF values. A low RCI indicates greater biomass in twospecies communities than would be expected from monocultures (i.e., a strong competitor). Solid lines and filled circles from 2017, dashed lines and filled triangles from 2018. Current data from 2016-2017, pre-existing data from 2003-2004. All correlations were significant $(P<0.05), \mathrm{R}^{2}=0.11-0.23$. Red, black and blue values represent negative, neutral and positive PSFs, respectively. 
A

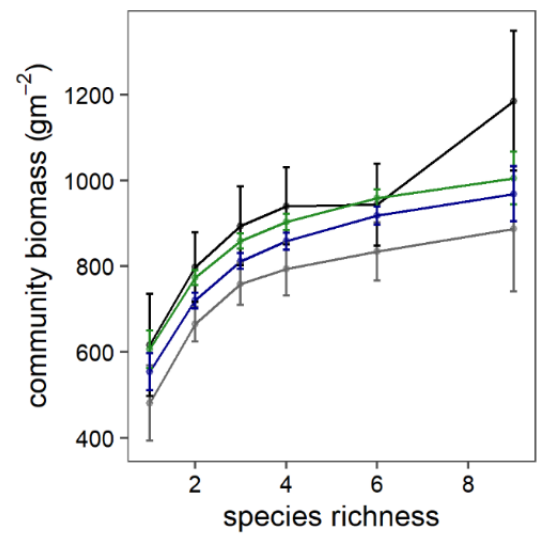

C

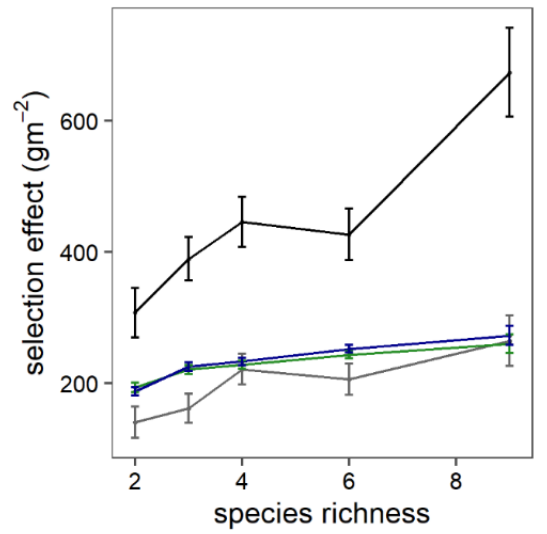

B

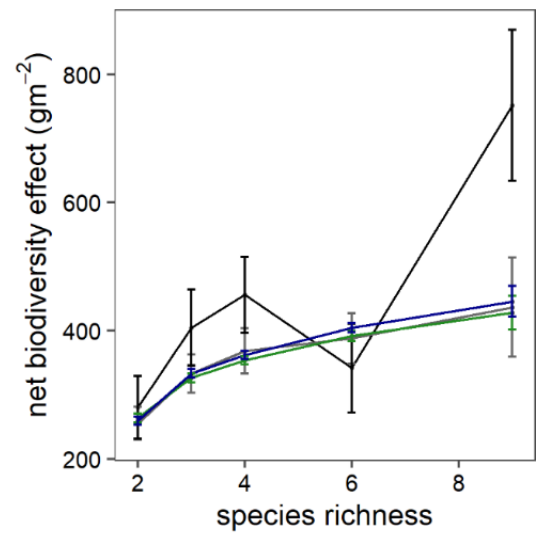

D

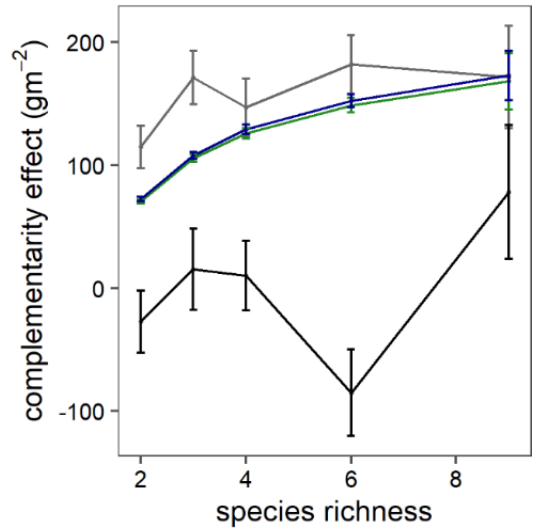

Fig. 4 Observed and predicted species richness effects for (A) community biomass, (B) net biodiversity effects, (C) selection effects, and (D) complementarity effects. Data from a current (2016-2017) and preexisting experiments (2003-2004; Roscher et al. 2004) shown in black and grey, respectively. Null and PSF model predictions shown in green and blue, respectively. Standard error bars shown represent error from replicate field plots. Statistical analyses in Supplementary Tables 1 and 2. 

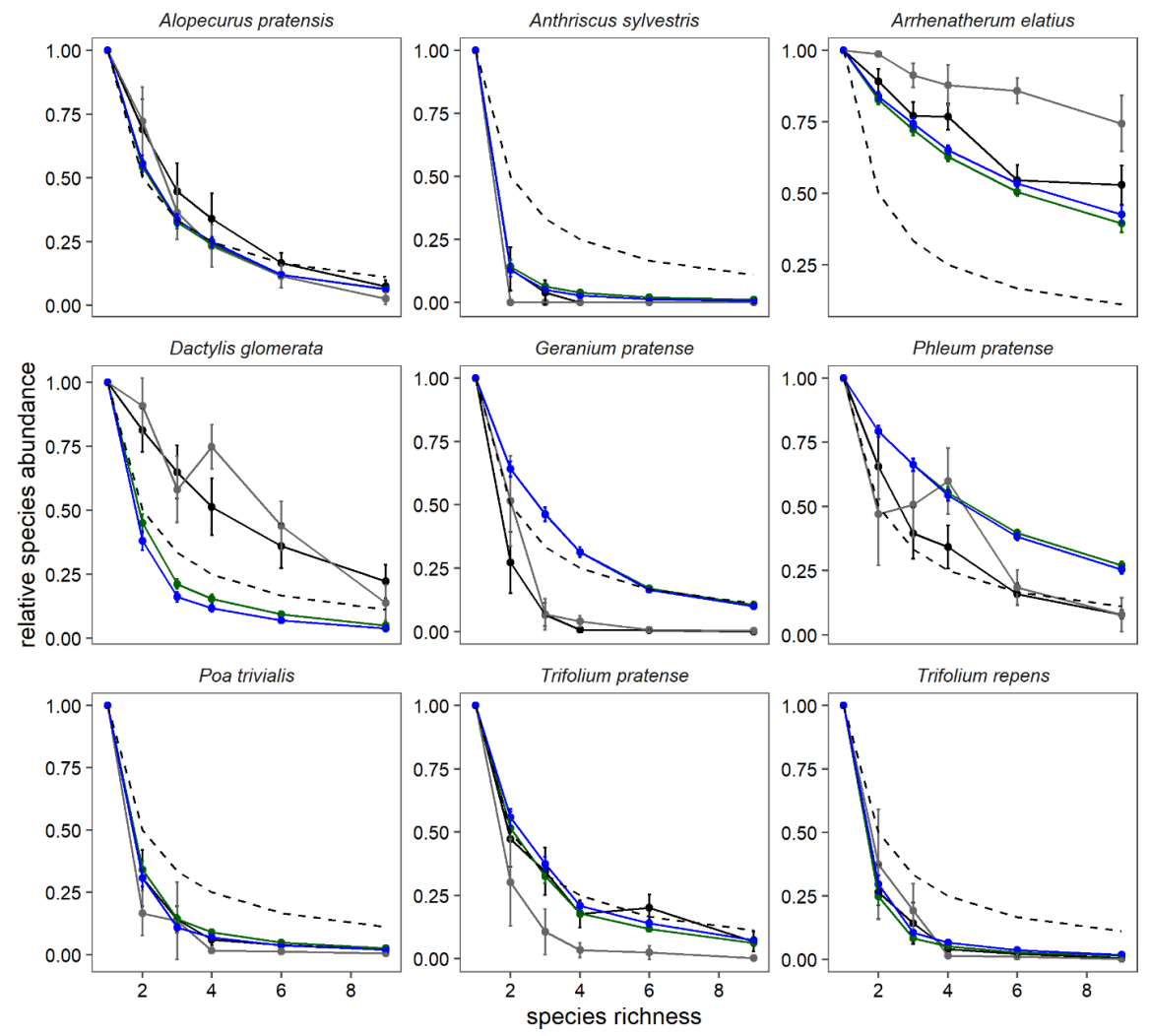

Fig. 5 Observed and predicted relative abundance for nine target species. The dashed line represents a default prediction of plant growth which was calculated as 1 /species richness. Observed and modeled data (solid lines) located above the dashed line indicates that a species was more productive in communities than would be predicted (i.e., overyield). Observed data from a current experiment (2016-2017) and a pre-existing experiment (2003-2004, Roscher et al. 2004) shown in black and grey, respectively. Null and PSF model predictions shown in green and blue, respectively. Statistical analyses in Supplementary Table 4. 